\title{
DOSE-DEPENDENT CHRONIC TOXICITY SCREENING OF HINOKITIOL IN ZEBRAFISHES: BEHAVIORAL AND HISTOLOGICAL APPROACH
}

\author{
KRISHNAPRIYA MADHU VARIER, SUMATHI THANGARAJAN*
}

Department of Medical Biochemistry, Dr. A. L. M. Post Graduate Institute of Basic Medical Sciences, University of Madras, Taramani Campus, Chennai, Tamil Nadu, India. Email: drsumathi.bioscience@gmail.com

Received: 12 July 2019, Revised and Accepted: 19 November 2019

\section{ABSTRACT}

Objectives: Parkinson's disease (PD) is categorized as a movement disorder symptomized by weakening the motor skills of the patients. The root cause of the disease is the neurodegenerative dopaminergic loss in the substantia nigra of the patient's brain. This havoc disease majorly affects the people above the age of 60 years. Moreover, PD incidences strike almost 70\% of the neurological disorders of the aged population worldwide. There are no perfect curative drugs in the medical world for the disease. Since the past few decades, several plant secondary compounds were in preclinical trials to treat this disease. Hinokitiol (HIN), a monoterpenoid from the heartwood of cupressaceous plants, is widely used in hair tonics, toothpaste, cosmetics, and food as an antimicrobial agent. It is well reported as an anti-stroke agent as well.

Methods: In the present study, the dose-dependent $(5,10,15,20$, and $25 \mathrm{mg} / \mathrm{kg})$ chronic toxicity of HIN was studied for 28 days using zebrafishes. The toxicity was analyzed in vital organs such as brain, liver, kidney, spleen, heart, and blood count followed by behavioral toxicity to target the drug against parkinsonism.

Results: The study revealed that the higher doses of 20 and $25 \mathrm{mg} / \mathrm{kg} \mathrm{HIN}$ treatment were toxic to the fish brain, spleen, as well as cardiomyocytes. It showed a variation in blood count as well at $10 \mathrm{mg} / \mathrm{kg}$ dose itself.

Conclusion: Hence, the study revealed the protective efficacy of the HIN at its therapeutic dosage of $5 \mathrm{mg} / \mathrm{kg}$ as a neuroprotective drug, with minimal vital organ toxicities.

Keywords: Zebrafishes, Hinokitiol, Motor impairment, Anxiety, Vital organ toxicity.

(C) 2020 The Authors. Published by Innovare Academic Sciences Pvt Ltd. This is an open access article under the CC BY license (http://creativecommons. org/licenses/by/4. 0/) DOI: http://dx.doi.org/10.22159/ajpcr.2020.v13i1.34892

\section{INTRODUCTION}

Parkinson's disease (PD) is the world's second most widespread movement disorder causing deterioration to the patient's normal movements and balanced postural abilities. The pathology behind this disease is the considerable loss of dopaminergic cells in the substantia nigra of the affected individual. The PD incidences were reported more in persons having an age above 60; hence, the disease is considered as an age-related disorder. Around 15 persons/1 lakh were reported as parkinsonians, as per recent report [1]. This disease even though not fatal exercises a great difficulty in the quality of life of a person. The perfect therapeutic drug for the disease is still unknown. Since the past decade, certain bioactive plant secondary compounds such as polyphenols, flavonoids, and coumarins were used as the drugs at its preclinical trial stages to treat PD symptoms while there is no precise healing medication for the disease brain [2].

Hinokitiol (HIN), a tropolone-related compound found in the heartwood cupressaceous plants, is widely used in hair tonics, toothpaste, cosmetics, and food as and as antineuralgic agent. The HIN even acts as an oxidative species scavenging agent, anticancer agent, and a mushroom tyrosinase inhibitor. Tropolone was testified as dominant inhibitors of cholesterinase receptors in brain [3]. Furthermore, the drug processes defensive mechanistic against the brain stroke induced in rats [4]. However, Li et al. [3] proved that HIN induces DNA damage, autophagy, and cell cycle arrest in S-phase in lung adenocarcinoma cell lines in vitro, at very high dosages. Thus, the therapeutic dosage fixation for the drug becomes highly relevant for the selection of a drug.

In addition to the routine animal models, recently, zebrafish were gaining much attention as a toxicological model due to their small size and easy husbandry. In addition, they entertain very small laboratory space with optimum breeding and maintenance conditions [5]. In contrast to larger species, the minute size of the adult zebrafish curtails costs through minimum quantities of medicating solutions (experimental chemicals, drugs, and pollutants), for both treatment and histological assessments (small amount of embedding materials and microscope slides) [6]. Moreover, the zebra fish models are now a days are used for reproductive toxicity, developmental toxicity, acute toxicity, neurotoxicity, cardiotoxicity, ocular toxicity, endocrine disruption, neurobehavioral toxicity, vascular toxicity, as well as carcinogenicity. For instance, zebrafish heart has been used as a model for human cardiovascular diseases and also is commonly affected during toxicity studies, usually manifesting as bradycardia or an arrhythmia [7]. Transgenics have also been used to help determine 2,3,7,8-Tetrachlorodibenzodioxininduced neurotoxicity through assessing changes in sonic hedgehog and neurogenin expression in the zebrafish brain [8]. Thus, as a pioneer toxicity study, HIN was analyzed at different doses using zebrafish models, by behavioral and histopathological studies to target it as an antiparkinsonian drug by finding its therapeutic dosage as well the ability of the drug to offer neuroprotection in peculiar concentration at posterior tuberculum, the origin of dopaminergic neuronal loss (similar to substantia nigra in humans).

\section{METHODS}

\section{Animals}

Wild-type adult zebrafishes considered under this study were maintained in accordance with the Institutional Animal Ethics Committee (IAEC No: 01/01/2017) and the Committee for the Purpose of Control and Supervision of Experiments on Animals, India, were followed with adherence to established protocols. Fishes were fed 
with commercial fish feed pellet. The water was changed regularly to maintain standard conditions. Groups of 12 adult fishes of both sexes were housed at light/dark cycle of 14/10 in $10 \mathrm{~L}$ water tanks with continuous aeration and biofiltration. The water parameters such as temperature, $\mathrm{pH}$, and conductance were maintained at $26-28^{\circ} \mathrm{C}, 6.3-$ 7.4, and 300-480 $\mu \mathrm{S}$, respectively. Fishes were housed in $3 \mathrm{~L}$ tanks at different dilutions and treated with compound orally for 28 days. To prepare dilutions of 5-25 mg stock, $13 \mathrm{mg}$ compound was dissolved in $5 \mathrm{ml}$ of $0.1 \%$ dimethyl sulfoxide and olive oil to make $2.5 \mathrm{mg} / \mathrm{ml}$ of stock, stored at $-20^{\circ} \mathrm{C}$ until use. Compound was diluted to a final concentration of 5-25 mg, respectively, to make the feed. This was then used in preparing fish feed. The known concentration of the compound is added to commercially available fish feed and air-dried before feeding.

\section{Dosing}

Adult male fishes were fed with the known concentration of the feed every $24 \mathrm{~h}$ for 28 days, according to the following groups: Group 1 served as control with vehicle; Group 2 with $5 \mathrm{mg} / \mathrm{kg}$ HIN; Group 3 with $10 \mathrm{mg} / \mathrm{kg}$ HIN; Group 4 with $15 \mathrm{mg} / \mathrm{kg}$ HIN; Group 5 with $20 \mathrm{mg} / \mathrm{kg} \mathrm{HIN}$, and Group 5 with $25 \mathrm{mg} / \mathrm{kg}$ HIN. All drugs and vehicle were administered orally.

\section{Behavioral cognitive study}

Before dissection on the $28^{\text {th }}$ day, the study groups were observed for cognitive behavior using dive tank test and swim motion test. Fishes were allowed to swim in the study tank and videos were captured using Mac CMOS 5MP motion capture lens [9].

\section{Histopathological analysis}

Post-exposures to compound for 28 days, fishes were euthanized and dissected as per ethical guidance. Fishes were anesthetized with $15^{\circ} \mathrm{C}$ water and sacrificed. Brain was dissected with a pin and knife. The brain, heart, liver, spleen, and kidney tissue were smeared on a glass slide and stained with hematoxylin and eosin, respectively, for $2 \mathrm{~min}$ each followed by phosphate-buffered saline washes. Slides were viewed at $\times 45$ using Labomed LX400 microscope [10].

\section{Quantification of damaged cells}

Smear slides were observed under bright field microscope and the number of damaged and normal cells was counted per cubic $\mathrm{cm}$. Red blood counts (RBCs) were counted per field and white blood cells
(WBCs) were quantified as mean differential count as percentage of total WBCs in blood.

\section{RESULTS}

Effect of HIN in the histopathological changes in posterior tuberculum of control and experimental fishes

HIN affected non-significant way on the posterior tubercular cells in lower dosages of 5, 10, and $15 \mathrm{mg} / \mathrm{kg}$ b.w. of fishes (Fig. 1). However, at increased dose of $20 \mathrm{mg} / \mathrm{kg}$ dose, it showed a toxic effect by the formation of intracellular spaces and lacunae, which tremendously decreased in $25 \mathrm{mg} / \mathrm{kg}$ dose.

Data represent mean \pm SD of 12 fishes in each group. (a) $p<0.01$ and (b) $\mathrm{p}<0.05$; ns: Not significant, were executed by one-way ANOVA with Tukey's post hoc test.

Effect of HIN in the histopathological changes in liver hepatocytes of control and experimental fishes

The hepatocytes in the liver cells were not significantly affected with the administration of HIN from 5 to $25 \mathrm{mg} / \mathrm{kg}$ doses (Fig. 2). However, very mere shear damage was observed in the $20 \mathrm{mg} / \mathrm{kg} \mathrm{HIN}$-administered fishes, which were highly insignificant statistically, thus proving null toxicity at all the five selected doses.

Data represent mean $\pm S D$ of 12 fishes in each group. (a) $p<0.01$ and (b) p<0.05; ns: Not significant, were executed by one-way ANOVA with Tukey's post hoc test.

Effect of HIN in the histopathological changes in kidney renal hepatocytes of control and experimental fishes

The renal hepatocytes even though exhibited a reduction in its normal hepatocyte number, those diminutions were highly inconsequential as far as toxicity studies were concerned (Fig. 3). However, the $5 \mathrm{mg} / \mathrm{kg}$ dose showed 5\% damaged hepatocyte counts which were highly nontoxic due to lack of mortality of treated fishes in that group for 28 days schedule.

Data represent mean $\pm S D$ of 12 fishes in each group. (a) $p<0.01$ and (b) $\mathrm{p}<0.05$; ns: Not significant, were executed by one-way ANOVA with Tukey's post hoc test.
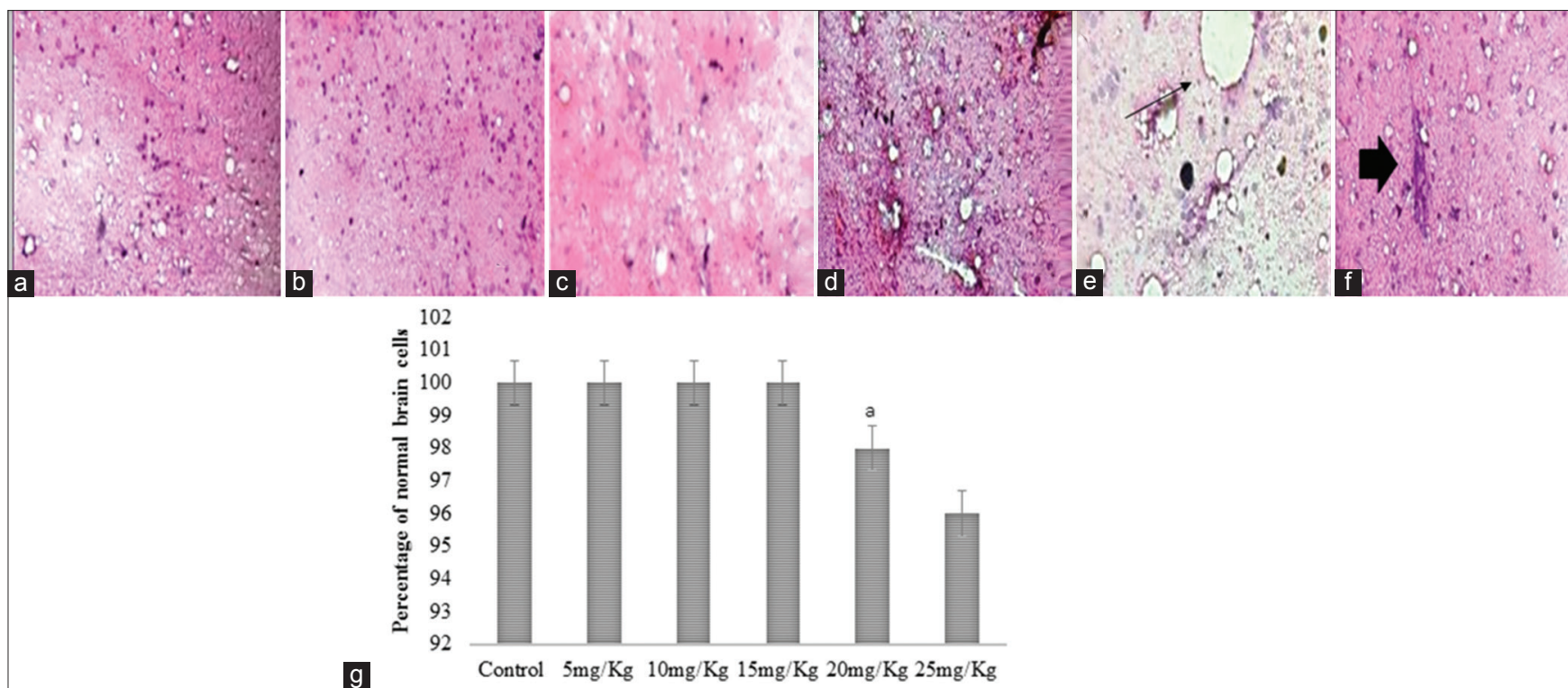

Fig. 1: Effect of Hinokitiol in the histopathological changes in posterior tuberculum of control and experimental fishes. Photomicrograph of $\mathrm{H}$ and $\mathrm{E}$ staining. (a) Control cells; (b) fishes treated with $5 \mathrm{mg} / \mathrm{kg}$ bwt of Hinokitiol; (c) fishes treated with $10 \mathrm{mg} / \mathrm{kg}$ bwt of Hinokitiol; (d) fishes treated with $15 \mathrm{mg} / \mathrm{kg}$ bwt of Hinokitiol; (e) fishes treated with $20 \mathrm{mg} / \mathrm{kg}$ bwt of Hinokitiol; (f) fishes treated with $25 \mathrm{mg} / \mathrm{kg}$ bwt of Hinokitiol $(\times 45)$ 


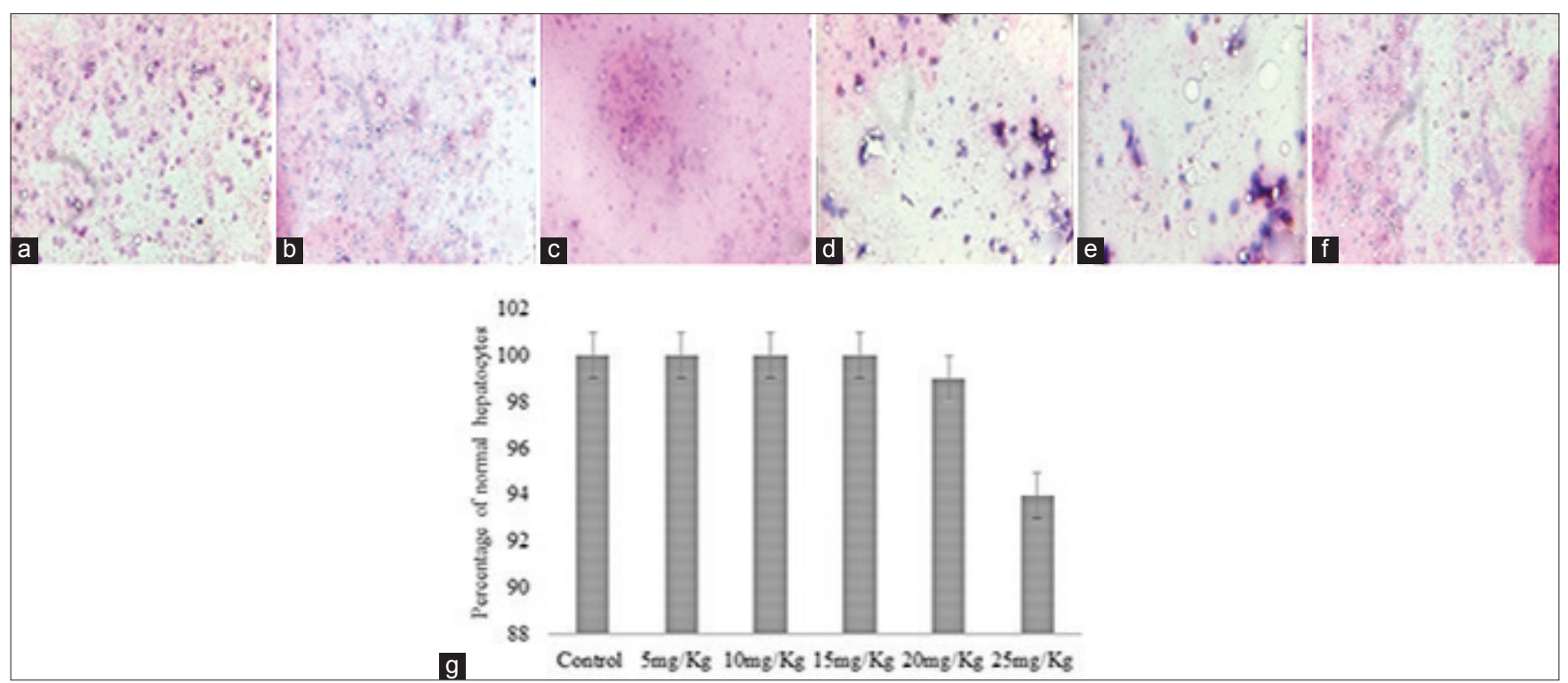

Fig. 2: Effect of Hinokitiol in the histopathological changes in liver hepatocytes of control and experimental fishes. Photomicrograph of $\mathrm{H}$ and E staining. (a) Control cells; (b) fishes treated with $5 \mathrm{mg} / \mathrm{kg}$ bwt of Hinokitiol; (c) fishes treated with $10 \mathrm{mg} / \mathrm{kg}$ bwt of Hinokitiol; (d) fishes treated with $15 \mathrm{mg} / \mathrm{kg}$ bwt of Hinokitiol; (e) fishes treated with $20 \mathrm{mg} / \mathrm{kg}$ bwt of Hinokitiol; (f) fishes treated with $25 \mathrm{mg} / \mathrm{kg}$ bwt of Hinokitiol $(\times 45)$

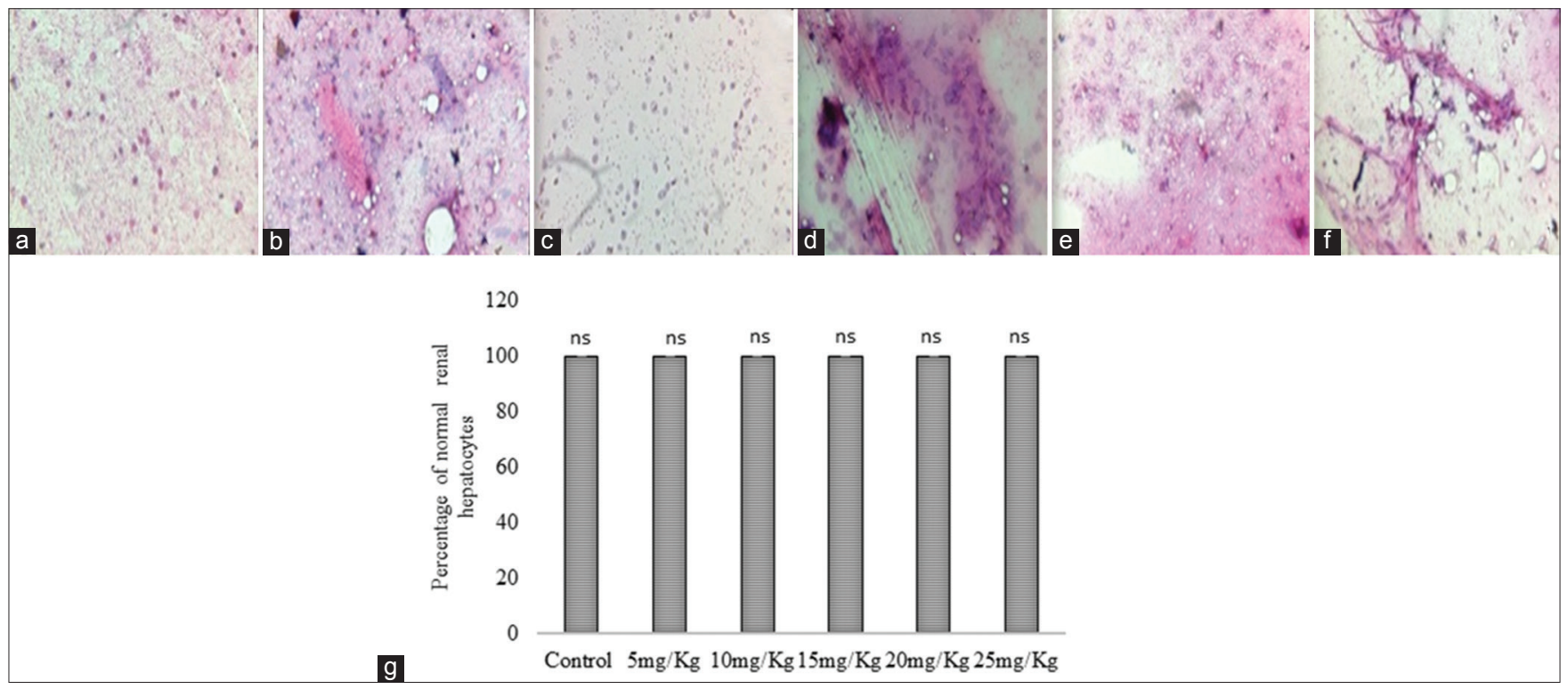

Fig. 3: Effect of Hinokitiol in the histopathological changes in kidney renal hepatocytes of control and experimental fishes.

Photomicrograph of $\mathrm{H}$ and $\mathrm{E}$ staining. (a) Control cells; (b) fishes treated with $5 \mathrm{mg} / \mathrm{kg}$ bwt of Hinokitiol; (c) fishes treated with $10 \mathrm{mg} / \mathrm{kg}$ bwt of Hinokitiol; (d) fishes treated with $15 \mathrm{mg} / \mathrm{kg}$ bwt of Hinokitiol; (e) fishes treated with $20 \mathrm{mg} / \mathrm{kg}$ bwt of Hinokitiol; (f) fishes treated with $25 \mathrm{mg} / \mathrm{kg}$ bwt of Hinokitiol $(\times 45)$

Effect of HIN in the histopathological changes in spleen cells of control and experimental fishes

The spleen cell reduction on administration with HIN was highly meager (non-significant) when compared to control group vehicletreated fishes for the entire period of the study (Fig. 4), for all the five doses $(5,10,15,20$, and $25 \mathrm{mg} / \mathrm{kg})$.

Data represent mean $\pm S D$ of 12 fishes in each group. (a) $\mathrm{p}<0.01$ and (b) $\mathrm{p}<0.05$; ns: Not significant, were executed by one-way ANOVA with Tukey's post hoc test.

Effect of HIN in the histopathological changes in cardiomyocytes of control and experimental fishes

The cardiomyocytes damage on administration with HIN was compared with control group vehicle-treated fishes after the dissection and staining. The study projected null toxicity with $100 \%$ healthy cardiomyocytes at $5 \mathrm{mg} / \mathrm{kg}$ dosed fishes (Fig. 5), while there was a sheer insignificant reduction in its count at 10 and $20 \mathrm{mg} / \mathrm{kg}$ dosed fishes (1\%), which were replenished at $25 \mathrm{mg} / \mathrm{kg}$ dosed fishes.

Data represent mean \pm SD of 12 fishes in each group. (a) $p<0.01$ and (b) $p<0.05$; ns: Not significant, were executed by one-way ANOVA with Tukey's post hoc test.

Effect of HIN in blood smear indicating total and differential blood count in both control and experimental fishes

The blood count (RBC) was somehow maintained between 3.1 and $3.2 \times 10^{6}$ in both control and experimental fishes (Fig. 6). However, the $20 \mu \mathrm{g} / \mathrm{ml}$ dosed fishes reduced its RBC count to $2.9 \times 10^{6}$, even though it continued to be far away from the toxicity levels, leading 


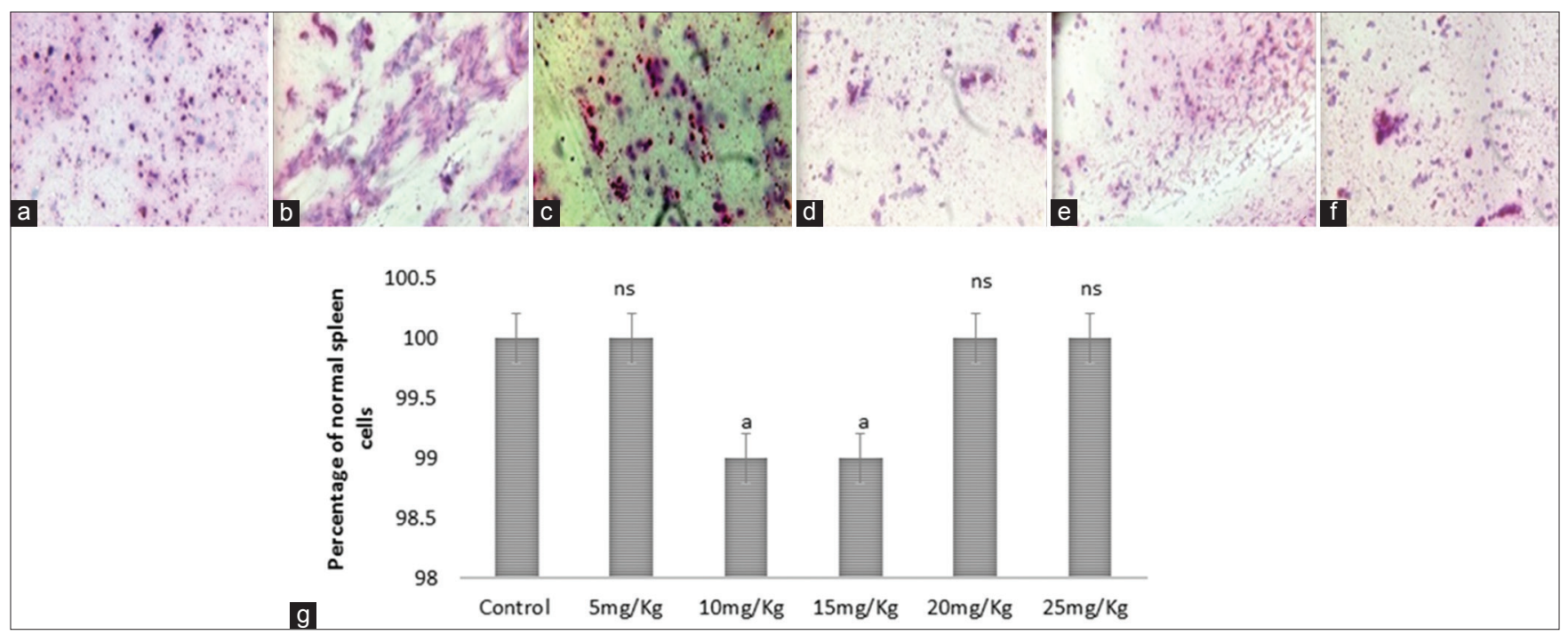

Fig. 4: Effect of Hinokitiol in the histopathological changes in spleen cells of control and experimental fishes. Photomicrograph of $H$ and $E$ staining. (a) Control cells; (b) fishes treated with $5 \mathrm{mg} / \mathrm{kg}$ bwt of Hinokitiol; (c) fishes treated with $10 \mathrm{mg} / \mathrm{kg}$ bwt of Hinokitiol; (d) fishes treated with $15 \mathrm{mg} / \mathrm{kg}$ bwt of Hinokitiol; (e) fishes treated with $20 \mathrm{mg} / \mathrm{kg}$ bwt of Hinokitiol; (f) fishes treated with $25 \mathrm{mg} / \mathrm{kg} \mathrm{bwt} \mathrm{of}$ Hinokitiol $(\times 45)$

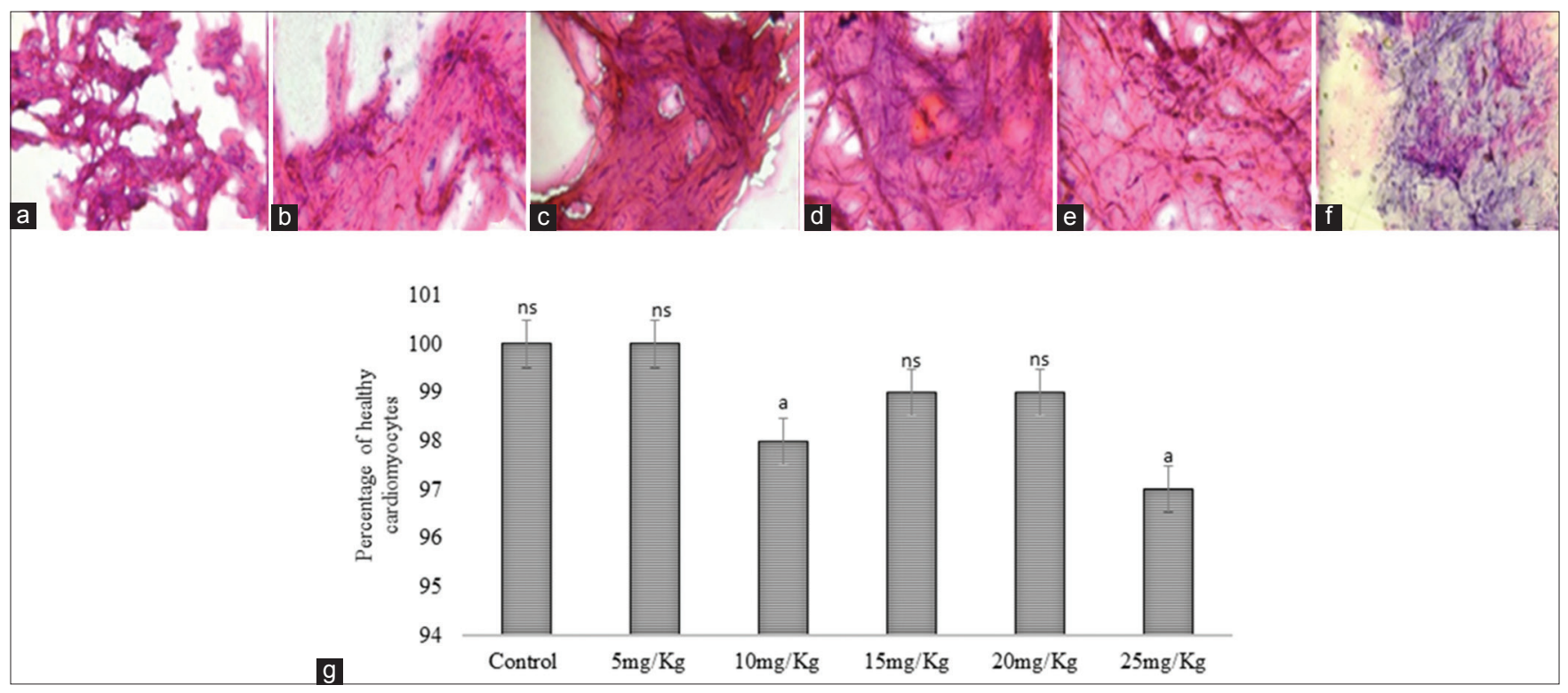

Fig. 5: Effect of Hinokitiol in the histopathological changes in cardiomyocytes of control and experimental fishes. Photomicrograph of $\mathrm{H}$ and $\mathrm{E}$ staining. (a) Control cells; (b) fishes treated with $5 \mathrm{mg} / \mathrm{kg}$ bwt of Hinokitiol; (c) fishes treated with $10 \mathrm{mg} / \mathrm{kg} \mathrm{bwt} \mathrm{of}$ Hinokitiol; (d) fishes treated with $15 \mathrm{mg} / \mathrm{kg}$ bwt of Hinokitiol; (e) fishes treated with $20 \mathrm{mg} / \mathrm{kg}$ bwt of Hinokitiol; (f) fishes treated with $25 \mathrm{mg} / \mathrm{kg}$ bwt of Hinokitiol ( $\times 45)$

to fish mortality. However, the differential mean percentage of blood count remained same with the control vehicle-treated animals in all the selected doses.

Data represent mean \pm SD of 12 fishes in each group. (a) $\mathrm{p}<0.01$ and (b) p $<0.05$; ns: Not significant, were executed by one-way ANOVA with Tukey's post hoc test.

The effect of HIN in motor activity and anxiety of control and experimental fishes

The behavioral changes such as motor coordination and anxiety were affected at higher doses of $10-25 \mathrm{mg} / \mathrm{kg}$ which were statistically significant at $\mathrm{p}<0.05, \mathrm{p}<0.01$, and $\mathrm{p}<0.001$, respectively (Fig. 7), while $5 \mathrm{mg} / \mathrm{kg}$ exhibited insignificant toxicity rate. Even though higher doses indicated behavioral abnormalities, none of the animals showed mortality till the end of the chronic toxicity study period. Data represent mean \pm SD of 12 fishes in each group. (a) $p<0.01$ and (b) $p<0.05$; ns: Not significant, were executed by one-way ANOVA with Tukey's post hoc test.

\section{DISCUSSION}

An effective drug for an age-related degenerative disease like Parkinson's disease is the need of the hour, due to the prevalence of the disease in both developed and developing nations and lack of a proper curative treatment. Since the past two decades, many drugs such as syndopa and levodopa have been privileged in the market, they still failed to cure the disease as such, unlikely providing some symptomatic improvements in cognition and motor impairments of the patients. The secondary option was the bioactive plant secondary metabolites such as flavonoids, coumarins, carotenoids, saponins, terpenoids, and so on. One such monoterpenoid HIN was our drug of choice since terpenoids 


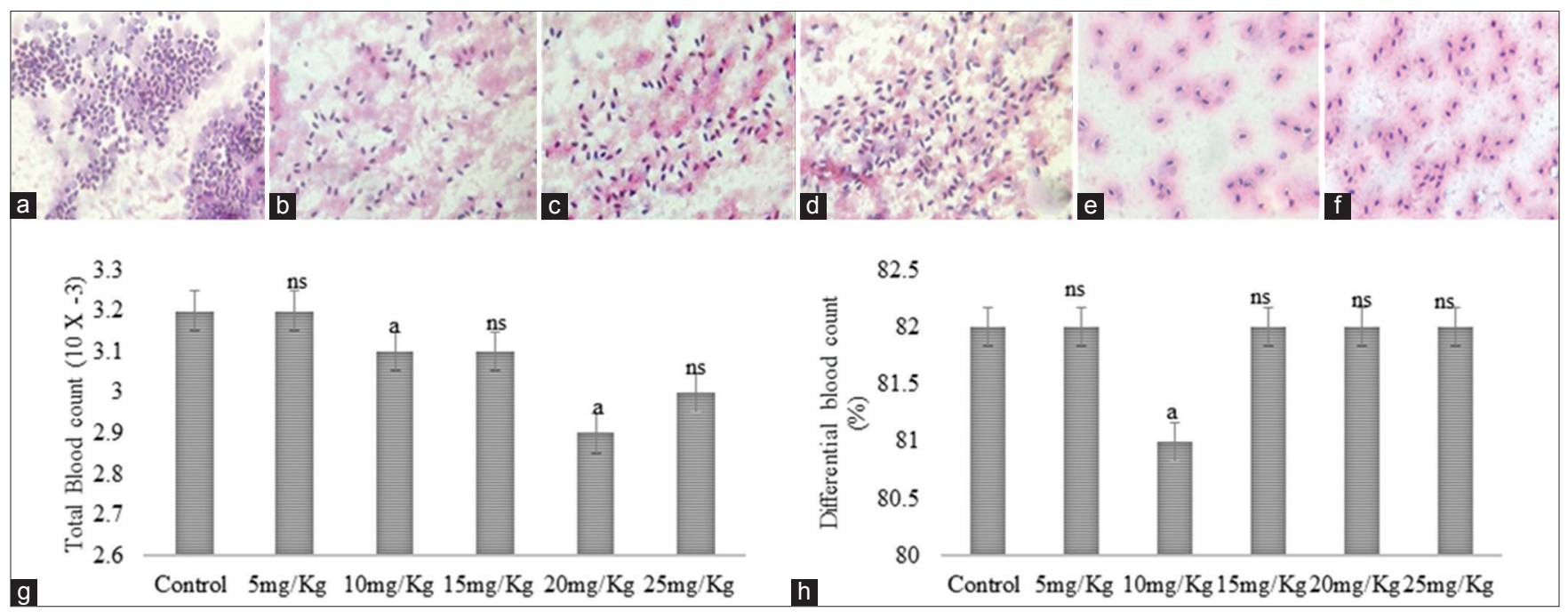

Fig. 6: Effect of Hinokitiol in blood smear indicating total and differential blood count in both control and experimental fishes. Photomicrograph of $\mathrm{H}$ and $\mathrm{E}$ staining. (a) Control cells; (b) fishes treated with $5 \mathrm{mg} / \mathrm{kg}$ bwt of Hinokitiol; (c) fishes treated with $10 \mathrm{mg} / \mathrm{kg}$ bwt of Hinokitiol; (d) fishes treated with $15 \mathrm{mg} / \mathrm{kg}$ bwt of Hinokitiol; (e) fishes treated with $20 \mathrm{mg} / \mathrm{kg}$ bwt of Hinokitiol; (f) fishes treated with $25 \mathrm{mg} / \mathrm{kg}$ bwt of Hinokitiol (×45)

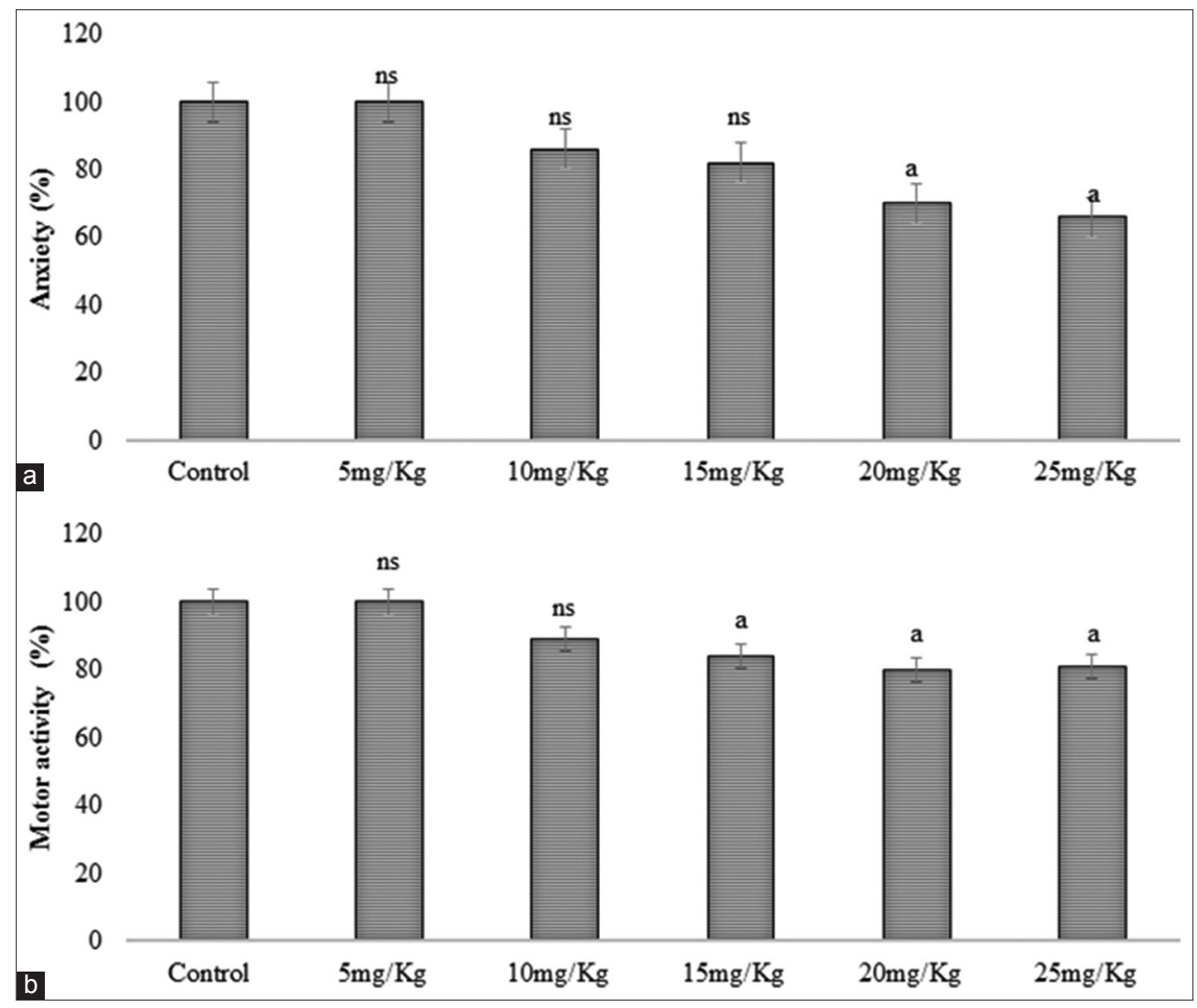

Fig. 7: The effect of Hinokitiol in motor activity and anxiety of control and experimental fishes

in minute doses were reported as cytoprotective agents [4]. Thus, in this study, the doses were fixed in lower ranges from 5 to $25 \mathrm{mg} / \mathrm{kg}$ b.w. of the animals.

Before we introduce a drug for the society, many pre-clinical and clinical studies have to be executed for studying their metabolism for the fixation of the therapeutic doses. For the same, toxicity testing is the principal screening methodology adopted by scientists for the newly developed drugs before it can be used on humans. This process mainly involves the determination of vulnerabilities of a test substance/ compound which may likely produce through its mechanism of action in a lively body; either animals or humans; pre-clinically in animals. These studies facilitate controlled exposure, duration of exposure, and the possibility of detailed examination of all tissues following damage [11], through histopathological estimations [12]. Our study has been postulated, thus through the histopathological analysis of the vital organs of the fish models.

Very recently, zebrafish, as a model vertebrate for toxicology, pharmacology, developmental biology, and genetics research, have been nurturing [13]. Moreover, the comparative usage of zebrafish in 
behavioral neuroscience overpowers that of rodents due to the easy execution of the toxicity screening tests which minimum amount of drug. In addition, the therapeutic endpoints in zebrafishes are much evident to trace than in other mammal models [14]. For neurotoxicological studies, zebrafish have well established neuroendocrine systems solely homologous to humans mediated by cortisol activated by the series of hypothalamo-pituitary hormones which are activated through glucocorticoid receptor [15]. Moreover, the neuroanatomy of the brain of mammals and zebrafishes also projects more than 95\% similarity in structure. Zebrafish possess all major neuromediator systems, including neurotransmitter receptors, transporters, and enzymes of synthesis and metabolism, similar to those observed in humans and rodents [16]. Previously, our reports have shown the anti-PD effect of HIN, in silico [17]. Very recently, several drug delivery strategies have been introduced to the clinics. However, the correct method of delivery with correct dosage is still an area to be researched on. Thus, this study provides a novel insight into this regard [18]. From several decades, many animal models have been tried in this aspect [19]. However, very recently, high interest has been attributed to zebrafish models [20]. Thus, our study with the zebrafish model becomes relevant with respect to toxicity screening of HIN. The results showed the precise discrimination that the $5 \mathrm{mg} / \mathrm{kg}$ dose could act as a therapeutic dosage of neuroprotection. These results suggest the efficacy of the drug as a cytoprotective agent in the brain-related neurodegenerative diseases.

\section{CONCLUSION}

The drug HIN failed deliberately to cause any organ failure and toxicity in vital organs involved in metabolism such as brain, liver, kidney, spleen, and heart. However, cognitive toxicity is observed such as slower motor activity and mild anxiety at higher dosages like 10$25 \mathrm{mg} / \mathrm{kg}$ b.w. The compound was non-toxic at higher concentrations due to immortality of fishes till the end of the treatment schedule. Thus, from the study, $5 \mathrm{mg} / \mathrm{kg}$ b.w. could be projected as an optimum dosage for the application of HIN as a drug of choice for brain-related studies, due to its blood-brain barrier crossing activity as well. Further, mechanistic research is required to confirm the same.

\section{AUTHORS' CONTRIBUTIONS}

KMV: Data curation, validation, and writing - original draft preparation. ST: Conceptualization, methodology, and formal analysis.

\section{CONFLICTS OF INTEREST}

All authors report no conflicts of interest regarding this manuscript.

\section{REFERENCES}

1. Gourie-Devi M. Epidemiology of neurological disorders in India: Review of background, prevalence and incidence of epilepsy, stroke, Parkinson's disease and tremors. Neurol India 2014;62:588-98.

2. Varier KM, Thangarajan S, Chinnasamy A. Effect of imperatorin in neuropathology of Parkinson's disease: An in silico study. Int J Pharm Clin Res 2017;9:599-609.
3. Li LH, Wu P, Lee JY, Li PR, Hsieh WY, Ho CC, et al. Hinokitiol induces DNA damage and autophagy followed by cell cycle arrest and senescence in gefitinib-resistant lung adenocarcinoma cells. PLoS One 2014;9:e104203.

4. Jayakumar T, Hsu WH, Yen TL, Luo JY, Kuo YC, Fong TH, et al. Hinokitiol, a natural tropolone derivative, offers neuroprotection from thromboembolic stroke in vivo. Evid Based Complement Alternat Med 2013;2013:840487.

5. Westerfield M. The Zebrafish Book: A Guide for the Laboratory Use of Zebrafish (Brachydanio rerio). Eugene, OR: University of Oregon Press; 1995.

6. Hill AJ, Howard CV, Cossins AR. Efficient embedding technique for preparing small specimens for stereological volume estimation: zebrafish larvae. J Microsc 2002;206:179-81.

7. Blechinger SR, Warren JT Jr., Kuwada JY, Krone PH. Developmental toxicology of cadmium in living embryos of a stable transgenic zebrafish line. Environ Health Perspect 2002;110:1041-6.

8. Hill A, Howard CV, Strahle U, Cossins A. Neurodevelopmental defects in zebrafish (Danio rerio) at environmentally relevant dioxin (TCDD) concentrations. Toxicol Sci 2003;76:392-9.

9. Tierney KB. Behavioural assessments of neurotoxic effects and neurodegeneration in zebrafish. Biochim Biophys Acta 2011;1812:381-9.

10. Ramachandran S, Thangarajan S. A novel therapeutic application of solid lipid nanoparticles encapsulated thymoquinone (TQ-SLNs) on 3-nitroproponic acid induced Huntington's disease-like symptoms in Wistar rats. Chem Biol Interact 2016;256:25-36.

11. Agrawal SS, Paridhavi M. Herbal Drug Technology. India: Universities Press; 2007. p. 607-14.

12. Klaassen CS. Principle of toxicology and treatment of poisoning. In: Parker BK, Blumenthal D, Buxton L, editors. Goodman and Gilman's; Manual of Pharmacology and Therapeutics. New York: McGraw Hill; 2008. p. 1115-9.

13. Jayshree N, Aparna S, Deepti A, Cynthia PP, Karthick S, Raja N. Proteinaceous compounds from Fragaria ananassa fruit attenuates paraquat induced Parkinson like locomotor and mitochondrial alterations in zebrafish. Int J Pharm Pharm Sci 2015;7:246-51.

14. Hill AJ, Teraoka H, Heideman W, Peterson RE. Zebrafish as a model vertebrate for investigating chemical toxicity. Toxicol Sci 2005;86:6-19.

15. Griffiths BB, Schoonheim PJ, Ziv L, Voelker L, Baier H, Gahtan E. A zebrafish model of glucocorticoid resistance shows serotonergic modulation of the stress response. Front Behav Neurosci 2012;6:68

16. Chen YC, Priyadarshini M, Panula P. Complementary developmental expression of the two tyrosine hydroxylase transcripts in zebrafish. Histochem Cell Biol 2009;132:375-81.

17. Krishnapriya MV, Sumathi T, Arulvasu C, Gopalsamy B, Renjith P. Comparative analysis of potentiality of esculin and hinokitiol (B-thujaplicin) as anti-parkinsonism drugs: A pilot in silico study. Int J Pharm Pharm Sci 2017;9:108-15.

18. Anitha P, Bhargavi J, Sravani G, Aruna B, Ramkanth S. Recent progress of dendrimers in drug delivery for cancer therapy. Int J Appl Pharm 2018;10:34-42.

19. Shamima NA, Biswajit D, Jashabir C. Prospective and retrospective animal model used in the pharmacological screening of anti-cancer drug. Int J Appl Pharm 2018;10:13-8.

20. Doris K, Kwabena O. Dosage forms of herbal medicinal products and their stability considerations-an overview. J Crit Rev 2017;4:1-8. 